\title{
UNA NUEVA PROBABLE GLEICHENIÁCEA DEL PÉRMICO INFERIOR DE PATAGONIA, ARGENTINA
}

\author{
Silvia N. CÉSARI', Néstor R. CÚNEO²y \\ Sergio ARCHANGELSKY $Y^{3}$ \\ 'Departamento de Geología. Facultad de Ciencias. Exactas y Naturales. \\ Universidad de Buenos Aires. Ciudad Universitaria. 1428 Buenos Aires. \\ Argentina. \\ = Museo Paleontológico Egidio Feruglio. Av. 9 de Julio 65.5. 9100 Trelew. \\ Argentina. \\ "División Paleobotánica. Museo Argentino de Ciencias Nalurales. "B \\ Rivadavia". Av. Angel Gallardo 470. 1405 Buenos Aires. Argentina.
}

Césari, S.N., Cúneo, N.R. y Archangelsky, S. 1998. Una nueva probable gleicheniácea del Pérmico Inferior de Patagonia, Argentina. [A probable new gleicheniaceous fern from the Lower Permian of Patagonia, Argentina]. Revista Española de Paleontología, 13 (1), 81-92. ISSN ()213-6937.

\begin{abstract}
Sterile and fertile specimens are described as a new species of the fern Oligocarpia, O. patagonica Césari, Cúneo et Archangelsky. The material is found in Lower Permian strata of the Río Genoa Formation, Tepuel-Genoa Basin, West of Chubut province, Argentina. Previously, some specimens have been assigned to other general that possess sphenopteroid foliage and are eusporangiate. However, new and better specimens were found with annulate sporangia, allowing an assignation of the material to Oligocarpia, a genus that is unknown in Gondwana but is common in the Northern Hemisphere. The finding of up to tripinnate fronds indicates a low fragmentation suggesting hypoautochtonous conditions in the formation of taphocoenoses that include Oligocarpia. This plant was associated to other leptosporangiate as well as eusporangiate ferms, in taphonomic assemblages derived from an understorey that was dominated by hydro-hygrophilous plants that grew in proximal and distal sectors of a deltaic system.
\end{abstract}

Keywords: Argentina, Chubut, Lower Permian, ferns, palaeoecology.

\section{RESUMEN}

Se describen ejemplares estériles y fértiles de helechos que se refieren a una nueval especie de Oligoc(r)pia. O. paragonica Césari, Cúneo y Archangelsky. El material fue hallado en estratos del Pérmico Inferior, Formación Río Genoa, Cuenca Tepuel-Genoa, al oeste de la provincia de Chubut, Argentina. Determinaciones previas de algunas piezas sugerían relaciones con otros géneros con pínnulas esfenopterídeas y eusporangiados. Sin embargo, el hallazgo de nuevo material fértil mejor conservado permitió reconocer esporangios con anillo, y, por lo tanto, asignarlo a Oligocarpia, género que no es conocido en el Gondwana pero que tiene frecuentes representantes en el Neopaleozoico del Hemisferio Norte. La escalsa fragmentación del material (la fronde es hasta tripinnada), sugiere condiciones hipoautóctonas en la formación de las tafocenosis portadoras de Oligocarpia. Esta planta se hallaba asociada a otros helechos, tanto leptosporangiados como eusporangiados, en conjuntos tafonómicos que derivaron de un sotobosque dominado por elementos hidro-higrofíticos, localizados en sectores proximales y distales de un sistema deltaico.

Palabras clave: Argentina, Chubut, Pérmico Inferior, helechos, paleoecología.

\section{INTRODUCCIÓN}

Recientes investigaciones paleobotánicals y paleoecológicas realizadas en secuencias pérmicas de la región patagónica, por parte de dos de los autores (N.R.C. y S.A.), han brindado nuevos elementos, entre los que se destacan abundantes frondes de helechos. Las publicaciones sobre este grupo de pteridofitas son escasas y en general antiguas (Archangelsky, 1958; Archangelsky y de la Sotal, 1960; Herbst, 1963 ; Archangelsky y Cúneo, 1986 y Cúneo y Ar- 


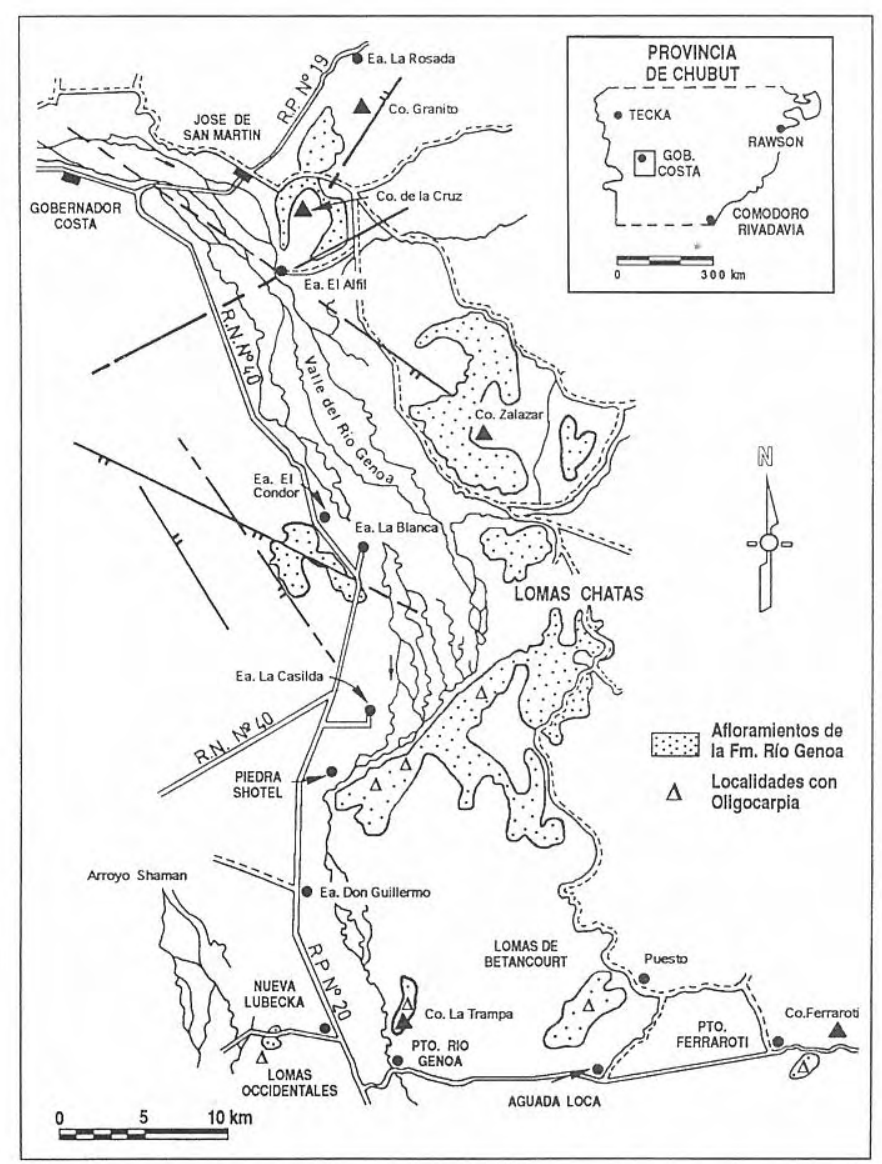

Figura 1. Mapa de ubicación de las localidades fosilíferas.

changelsky, 1987). Esta circunstancia motivó el interés en iniciar una revisión de las especies presentes tanto en la Cuenca Tepuel-Genoa (provincia de Chubut) como en la Cuenca La Golondrina (provincia de Santa Cruz), Argentina.

En esta contribución se describen frondes fértiles que son referidas al género Oligocarpia Göppert emend. Abbott, conocido en el Neopaleozoico paleoecuatorial y que no posee registros anteriores en Gondwana. Los primeros fragmentos reconocidos fueron dados a conocer por Cúneo (1987), quien en esa ocasión los denominó Sphenopteris sp. IV y Stellatheca sp. Posteriormente, en una presentación preliminar, dichos fragmentos se refirieron al género Renaultia Zeiller, puesto que no se habían observado esporangios con anillo (Archangelsky et al., 1995). Nuevo material recolectado en las mismas localidades, y estudios minuciosos con microscopía electrónica de barrido posibilitaron determinar la presencia de un anillo en los esporangios. Ello permite clasificar los fósiles tentativamente en el género Oligocarpia, helecho que se conoce por materiales que proceden de áreas alejadas de Patagonia de acuerdo a las reconstrucciones paleogeográficas corrientes.

\section{PROCEDENCIA ESTRATIGRÁFICA}

Todo el material estudiado procede de la Formación Río Genoa, unidad estratigráfica que representa la culminación del ciclo sedimentario del Paleozoico Superior en la Cuenca Tepuel-Genoa, al oeste de la provincia de Chubut (Fig. 1). Esta unidad corresponde al depósito de varios ciclos deltaicos con predominio de acción fluvial (Andreis y Cúneo, 1989), en cuyas facies de planicie deltaica superior, en particular sus sectores interdistributarios, fueron encontrados los restos aquí estudiados (Fig. 2). Los mismos se vinculan, por lo general, a los sectores estratigráficamente más altos de la Formación Río Genoa en las diversas localidades en que fueron hallados. Bioestratigráficamente, estos niveles corresponden a la parte inferior de la Zona de Ginkgoites eximia (Archangelsky y Cúneo, 1985; Cúneo, 1987), cuya edad sería, dentro del esquema cronoestratigráfico regional, Lubeckiano tardío (Pérmico temprano).

\section{MATERIAL Y MÉTODOS}

Los fósiles, conservados como improntas, se encontraron en un mismo evento sedimentario y han permitido una tentativa reconstrucción de la fronde. La misma es considerada hipotética pues, como lo señalaron Gastaldo y Boersma (1983), la población de una especie actual procedente de una misma localidad puede mostrar variabilidad en tamaño y desarrollo de las frondes, debido a razones de nutrición, condiciones edáficas y genéticas.

Se consideró en su reconstrucción la distancia de los ráquises laterales a lo largo del raquis principal, el grado de desarrollo de las pinnas y pínnulas, su espaciamiento y el espesor de los ráquises. En la figura 3, los ejemplares han sido dispuestos desde la supuesta región proximal a la distal de la fronde. Su posición fue esquemáticamente indicada, de tal manera que cada espécimen puede ser comparado con la fotografía correspondiente. En las ilustraciones los especímenes han sido orientados de acuerdo a su posición en la fronde, ubicando su ápice hacia el borde superior de la lámina.

Siguiendo a Brousmiche (1983), se han reconstruido las etapas de diferenciación del limbo pinnular, observando paso a paso el orden de aparición de lóbulos y su forma de crecimiento. Para ello se ha tomado en cuenta la conservación de los especímenes, dado que en algunos, las pínnulas presentan limbos de un aspecto globoso, y por ello los bordes no se observan con claridad.

E1 término pínnula es usado para señalar la última división del limbo foliar, esto es, la unidad más pequeña de la fronde. El raquis de último orden (orden "n") es el que porta las pínnulas, mientras que el raquis de penúltimo orden (orden n-1) es el que corresponde a la pinna de penúltimo orden, y así sucesivamente.

Los especímenes fueron examinados con lupa binocular y las fotografías fueron realizadas con una cámara Canon FX1 usando película T-max Kodak. Observación y fotografía con el microscopio electrónico de barrido fueron efectuadas con el equipo del Instituto Botánico Darwinion, San Isidro, Buenos Aires. El material se encuentra depositado en la Colección Paleobotánica del Museo Paleontológico Egidio Feruglio, con la sigla MPEF-PB y en la Colección Paleobotánica del Museo Argentino de Ciencias Naturales "B. Rivadavia", con la sigla BAPb. 


\section{DESCRIPCIÓN SISTEMÁTICA}

\author{
ORDEN FILICALES Engler y Prantl 1902
}

Familia Gleicheniaceae (Br.) Presl 1825

Género Oligocarpia Göppert emend. Abbott 1954

\author{
Especie tipo: Oligocarpia gutbieri Göppert 1841.
Oligocarpia patagonica Césari, Cúneo y Archangelsky sp. nov.
Figs. 4, 5 a, b, d, e, f y g, Lám I y II

Holotipo: Museo Paleontológico Egidio Feruglio MPEF-PB 50 (a y b), figuras 4 y 5 a, b, d, e, f y g.

Paratipos: MPEF-PB 51a y b (Lám. I, fig. 4), 52 a, b (Lám. I, fig. 5) y c (Lám. I, fig. 3) y BAPB 4531 a, b y c (Lám. II, fig. 7).

Otro material estudiado: MPEF-PB 53 (a y b), 54 (a y b), $55,56,57,58$ (a y b) y 59 (a y b).

Localidad tipo: Betancourt, 5 kilómetros al norte de Aguada Loca, localidad ubicada $15 \mathrm{~km}$ al este de la intersección de las rutas provinciales 20 y 23 , provincia de Chubut, Argentina.

Estrato tipo: Formación Río Genoa, Sección plantífera II, nivel fosilífero A (Fig. 2).

Etimología: de Patagonia, región geográfica del hallazgo.

\section{Diagnosis}

Frondes al menos tripinnadas, con ráquises alados ligeramente flexuosos. Los ráquises n-1 están alternadamente insertos a lo largo de los ráquises n-2 de la fronde. Los ráquises n están oblicuamente insertos y portan pínnulas anchamente adheridas, basalmente algo constrictas. El borde basal basiscópico de las pínnulas es fuertemente decurrente sobre el raquis. Las pínnulas más desarrolladas tienen $8-10 \mathrm{~mm}$ de largo, y presentan lóbulos con cortas indentaciones. Las pínnulas son ovadas a ovado-alargadas. Las pínnulas distales son coalescentes con las pínnulas adyacentes, oblicuamente cuneadas y de ápice obtuso. Una vena recta a levemente decurrente penetra en la base pinnular emitiendo lateralmente venas hacia los lóbulos. Las venas laterales se bifurcan una o dos veces con ángulo agudo hasta llegar al margen. Fructificaciones compuestas por esporangios leptosporangiados, submarginales, insertos sobre las venillas secundarias, cerca o en su extremidad, aislados o agrupados en número de 2 a 8 , formando soros subredondeados a ovalados. Esporangios provistos de un anillo, posiblemente transversal.

Fronds at least tripinnate with winged and slightly flexuous rachises. Rachises $n-1$ alternately inserted on the rachises $n-2$ of the frond. Rachises $n$ are obliquely inserted on the secondary axes and bear pinnules adhered widely and slightly constricted at their base. The basal basiscopic margin of pinnules strongly decurrent on rachis. Largest pinnules are $8-10 \mathrm{~mm}$ long and have lobes with short indentations. Pinnules are ovate to ovate-elongate. Distal pinnules coalesce with adjacent pinnules, and are obliquely cuneate with an obtuse apex. A straight, slightly decurrent vein enters the pinnule giving off lateral veins towards the lobes. Lateral veins fork once or twice at an acute angle and reach the margin. Fructifications composed of leptosporangiate, submarginal sporangia inserted on lateral veins near to or at their tip, single or in groups of 2-8, forming subrounded to oval sori. Sporangia with a probably transverse annulus.

\section{Descripción}

El holotipo (MPEF-PB 50) corresponde a un fragmento de fronde bipinnada, de $9 \mathrm{~cm}$ de largo (incompleto), con un raquis principal flexuoso de $1 \mathrm{~mm}$ de ancho (Fig. 4). Pinnas dispuestas alternadamente en ángulo de $70^{\circ}$, separadas una distancia de $1 \mathrm{~cm}$ o menor hacia el sector distal. Las pinnas miden hasta $4 \mathrm{~cm}$ de largo y presentan un raquis de $7 \mathrm{~mm}$ de ancho. Pínnulas con vena media decurrente de recorrido sinuoso, alternas, las de mayor tamaño miden $1 \mathrm{~cm}$ de largo por $5 \mathrm{~mm}$ de ancho basal; se cuentan hasta 16 por segmento. La vena media se diferencia hasta prácticamente el ápice, donde se divide en dos venas menores. Las demás venas secundarias son decurrentes y a veces vuelven a bifurcarse dos veces, la primera vez a mitad de su recorrido. Todas las pinnas de la fronde se encuentran fructificadas con soros marginales, dispuestos sobre la parte terminal de las venas secundarias. Hasta 8 esporangios ovales, de $0,25 \mathrm{~mm}$ de largo por $0,15 \mathrm{~mm}$ de ancho, se agrupan en un soro (a veces hay un esporangio central, Fig. 5 d). En ellos es posible observar un anillo de posición probablemente ecuatorial, formado por células engrosadas radialmente dispuestas (Fig. 5 a, b, f y g). La ubicación del espécimen correspondería a la parte distal de la fronde, de acuerdo a la reconstrucción hipotética (ver Fig. 3).

El espécimen MPEF-PB 53 (Lám. I, fig. 1) demuestra la relación del raquis principal (n-2) y el desarrollo de los ráquises laterales $(n-1)$ en una posición proximal de la fronde. Este ejemplar fue tomado como referencia para ubicar el resto de los fragmentos en la reconstrucción (ver Fig. 3). El raquis n-2 está longitudinalmente estriado, tiene un ancho visible de 2,5 $\mathrm{mm}$ y aparece ligeramente flexuoso. Los ráquises n-1 nacen aproximadamente a $80^{\circ}$ en forma alterna, son ligeramente sinuosos, están estriados y tienen un ancho de $0,8 \mathrm{~mm}$. La distancia entre ráquises $\mathrm{n}-1$ consecutivos es de $2 \mathrm{~cm}$. Portan oblicuamente pinnas oblongas, de orden $n$, insertadas alternadamente, siendo basiscópica la primera. La distancia entre pinnas es de 6 $\mathrm{mm}$. Las pinnas acroscópicas están insertas más perpendicularmente que las basiscópicas. La pinna más desarrollada observada es la tercera a partir del raquis principal (Lám. I, fig. 2; Fig. 6 B), con un largo de $26 \mathrm{~mm}$, y con sus pínnulas basales de hasta $8 \mathrm{~mm}$ de longitud. Las pínnulas son lobadas a prácticamente enteras, lo cual depende de su posición a lo largo de los ráquises n-1; tienen las bases algo constrictas, decurrentes y poseen ápices obtusos. En la Lámina I, fig. 2 se observa la continuidad de la lámina foliar a través de las 


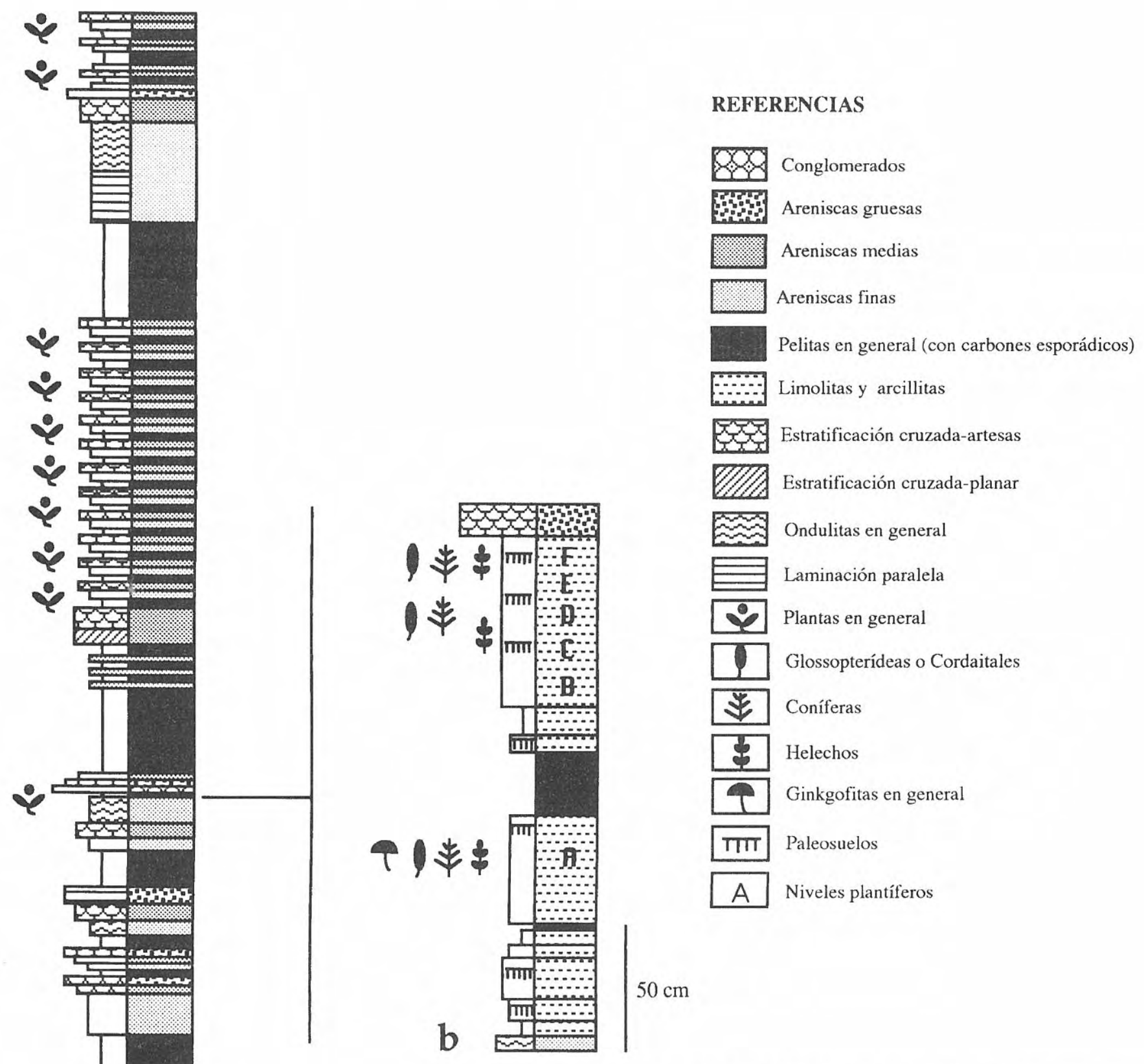

Figura 2. a: Sección tipo para Oligocarpia patagonica, localidad Betancourt, sección plantífera II, Formación Río Genoa, Pérmico Inferior, Chubut, Argentina. b: Detalle de la sección plantífera II, portadora del tipo de Oligocarpia patagonica en su nivel fosilífero A. La microsección corresponde a un depósito de planicie interdistributaria vinculado al sistema deltaico de la Formación Río Genoa en su sector meridional.

bases decurrentes, pudiéndose interpretar el conjunto como una sola unidad. En los sectores proximal y distal de la pinna de orden $\mathrm{n}-1$, hay 8 a 11 pínnulas por pinna de orden $\mathrm{n}$, mientras que en el sector medio (donde se encuentran más desarrolladas), hay 14. Las pínnulas distales o poco desarrolladas son cuneadas e inclinadas sobre el raquis y adheridas por toda su base (Lám. I, fig. 2). Un primer lóbulo se individualiza en el lado catadrómico, y los siguientes se diferencian alternadamente a ambos lados de la vena media.
Al aparecer el tercer lóbulo anadrómico, una primera incisión se desarrolla a nivel del lóbulo basal anadrómico. Los otros lóbulos se dividen alternadamente, pero siempre con un ligero desfase en su aparición, lo que provoca una cierta asimetría de la pínnula. Al lobularse, las pínnulas se alejan del raquis tomando una posición más erecta. Su borde anádromo es poco contraido, mientras que el catadrómico es más contraido y a la vez decurrente sobre el raquis. Una sola vena entra en cada pínnula y desarrolla tantos fascículos 
laterales alternos como lóbulos, siendo el primero basiscópico. Los fascículos laterales presentan una a dos dicotomías.

El espécimen MPEF-PB 51 muestra un eje principal, de orden $\mathrm{n}-1$, flexuoso, de $0,8 \mathrm{~mm}$ de ancho, portando ráquises laterales alternos de orden $n$, separados por una distancia que disminuye del sector proximal al distal de $10 \mathrm{~mm}$ a $4 \mathrm{~mm}$. La pinna más desarrollada (Lám. I, fig. 4), tiene un largo aproximado de $31 \mathrm{~mm}$ y lleva 9 pínnulas lobuladas, con sus bases ligeramente constrictas y decurrentes. El ejemplar se interpreta como una pinna lateral ubicada en un sector más proximal de la fronde que el ocupado por el ejemplar MPEFPB 53.

El ejemplar MPEF-PB 52c (Lám. I, fig. 3), correspondería al sector medio de una pinna lateral de orden $\mathrm{n}-1$, en un sector de la fronde más proximal que el ocupado por MPEF-PB 51. La distancia entre pinnas consecutivas es de $10 \mathrm{~mm}$, la más completa tiene $38 \mathrm{~mm}$ de largo y está compuesta por 13 pínnulas lobuladas, la primera basiscópica, insertas al raquis por una base más o menos contraída.

El ejemplar MPEF-PB 55 (Lám. II, fig. 2), es un fragmento tripinnado, con un raquis de orden n-2 el cual porta ráquises laterales de hasta $12 \mathrm{~cm}$ de largo, separados por una distancia de $20 \mathrm{~mm}$. Éstos llevan en forma alterna pinnas separadas por unos $4 \mathrm{~mm}$. La primera pinna es basiscópica y mide $16 \mathrm{~mm}$ de largo, mientras que la primera acroscópica mide $19 \mathrm{~mm}$ y tiene 11 pínnulas. Este espécimen ocuparía una posición más distal que MPEF-PB 53.

El espécimen que mejor demuestra la relación del raquis de orden n-2 y el desarrollo de pinnas distales de la fronde de orden n-1, es MPEF-PB 54 (Lám. II, fig. 1). Los ráquises de orden $\mathrm{n}-1$ portan pinnas de hasta $19 \mathrm{~mm}$ de largo. La distancia entre pinnas consecutivas es de $4 \mathrm{~mm}$. En promedio, presentan 7 lóbulos o pínnulas lobuladas. Las pínnulas están estrechamente espaciadas con una mínima constricción basal impartiendo una apariencia robusta y compacta a las pinnas.

El ejemplar MPEF-PB 52b (Lám. I, fig. 5) es un fragmento tripinnado, con un raquis principal de $1,5 \mathrm{~mm}$ que porta oblicuamente ejes laterales alternos, carenados y algo flexuosos, separados por unos $7 \mathrm{~mm}$. Estos ráquises laterales de orden n-1 llevan pinnas separadas $4 \mathrm{~mm}$. La primera pinna es basiscópica y presenta 7 pínnulas lobadas (Fig. 6A), con un largo de $14 \mathrm{~mm}$, mientras que la primera pinna acroscópica mide $15 \mathrm{~mm}$. La tercera pínnula basiscópica es la que presenta mayor desarrollo, con un largo de $15 \mathrm{~mm}$ y 8 pínnulas. Este fragmento ocuparía en la fronde un lugar más distal que MPEF-PB 54.

Finalmente, el espécimen MPEF-PB 56 (Lám. II, fig. 5), consta de un raquis principal, de $1 \mathrm{~mm}$ de ancho y aproximadamente $12 \mathrm{~cm}$ de largo. Lleva en forma subopuesta 24 pinnas. Las pinnas están separadas entre 1 y 2 $\mathrm{mm}$; las proximales miden $25 \mathrm{~mm}$ de largo y portan 12-14 pínnulas de $6 \mathrm{~mm}$ de largo, con 7 lóbulos redondeados. La distancia entre pínnulas es de $4 \mathrm{~mm}$. Existen dos posibilidades para interpretar su posición en la fronde. Una es que corresponda a un eje lateral de, por ejemplo, un sector equivalente al ejemplar MPEF-PB 52b. Sin embargo, la
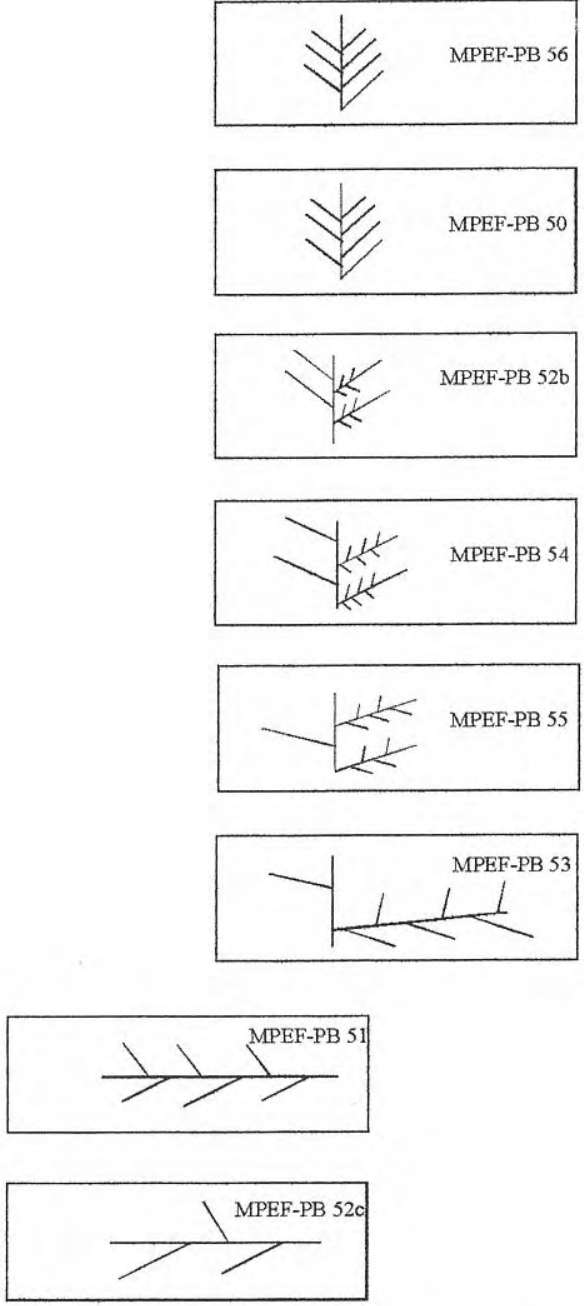

Figura 3. Reconstrucción esquemática de la fronde, con la posición de los distintos fragmentos estudiados.

separación entre pinnas es muy reducida y su disposición subopuesta no fue observada en otros ejemplares. Además, el largo de las pinnas es mayor que el de las equivalentes en MPEF-PB 52b para un mismo ancho de raquis. La opción más lógica parece sugerir su ubicación en un sector terminal de la fronde, donde las pinnas laterales se disponen más apretadamente y el tamaño de las pínnulas disminuye.

Los ejemplares fértiles no muestran diferencias en su morfología con los descriptos anteriormente. La muestra BAPB 4531 (Lám. II, figs. 3, 4 y 7) presenta fragmentos de pequeñas pinnas estériles y fértiles. De acuerdo al tamaño y separación de los segmentos, su ubicación en la fronde sería equivalente a la del ejemplar MPEF-PB 52b. Uno de los fragmentos estériles más completos (Lám. II, fig. 7) posee un raquis finamente estriado de $1 \mathrm{~mm}$ de ancho, que porta ejes laterales, insertados aproximadamente a $80^{\circ}$ y separados por una distancia de $5 \mathrm{~mm}$. La primera pinna es basiscópica y mide $1 \mathrm{~cm}$ de largo, tiene 9 pínnulas redondeadas, levemente lobuladas. La distancia entre pinnas es de $3 \mathrm{~mm}$ (Lám. II, fig. 7). Los fragmentos fértiles muestran características similares, salvo una conservación diferencial del limbo foliar, que resulta en pínnulas de aspecto más cuneado (Lám. II, fig. 4). En los ápices de estos lóbulos se 
encuentran esporangios subcirculares, densamente dispuestos, a veces radialmente en número de tres a cinco (Lám. II, fig. 3).

El ejemplar MPEF-PB 58a presenta un raquis de orden n, carenado o alado, de $1 \mathrm{~mm}$ de espesor, en el cual se puede distinguir el cordón vascular que mide $0,5 \mathrm{~mm}$. Las pínnulas, oblongas, con márgenes lobulados, se encuentran separadas 5 mm y miden $18 \mathrm{~mm}$ de largo (Lám. II, fig. 6). El margen basiscópico de la base pinnular es decurrente, mientras que el acroscópico es algo contraido. En cada pínnula entra una vena media, poco decurrente, de recorrido zigzagueante, de la cual nacen venillas laterales (la primera es basiscópica) que presentan una o dos dicotomías. En los extremos distales de las venillas (Fig. 5, c), se observan esporangios subcirculares dispuestos en grupos de hasta cinco.

La posición marginal de los esporangios y su agrupación en soros es muy característica. Cada soro está alimentado por una vena (Fig. 5 a, c y e ). La agrupación de los esporangios en los soros es irregular y no parece tener una simetría definida (Lám. II, fig. 6 y Fig. 5 a, b y d). Si bien los soros están ubicados muy cerca de o directamente sobre los márgenes, no se ha observado la presencia de un indusio.

\section{Comparaciones}

En una primera instancia, con poco material fértil, no se observó anillo en los esporangios (Archangelsky et al., 1995) y por lo tanto se refirió al género Renaultia Stur. El hallazgo de ejemplares adicionales permitió reconocer estructuras que muestran células engrosadas formando un anillo (Fig. 5, b, f y g, flechas). Este anillo parece ser completo y de posición probablemente ecuatorial en el esporangio. Estas características permiten clasificar nuestra especie en la familia Gleicheniaceae y, de acuerdo a su diagnosis, en el género Oligocarpia Göeppert emend. Abbott, aunque la ubicación geográfica de nuestro material es atípica.

En las especies del género actual Gleichenia existe variación muy marcada de los soros que se producen en una misma especie. Bower (1935, fig. 310 a-h) ilustra soros de $G$. dichotoma Willd. con seis esporangios radialmente dispuestos, hasta soros que por el elevado número de esporangios (10) forman grupos asimétricos que pueden estar en contacto lateral (Bower, op. cit., fig. $310 \mathrm{~g}, \mathrm{~h}$ ). Estas mismas características (y una posición submarginal de los soros) son destacadas por Bower (op. cit., fig. 312 b, c) para Oligocarpia brogniartii Stur. En este sentido, la ubicación de los soros depende de la extensión que presente la venación. Cuando ésta llega hasta los márgenes pinnulares, los soros tendrían la misma disposición, como es el caso de $O$. patagonica. La compacidad de los soros varía en un mismo individuo (véase Fig. 5 c y e).

De acuerdo con Brousmiche (1983), las especies fósiles de Oligocarpia deben diferenciarse sobre la base de sus órganos reproductivos, pues éstos tienen una marcada estabilidad morfológica frente a la variabilidad de la parte vegetativa. Cabe señalar que el género posee pínnulas tanto esfenopterídeas como pecopterídeas. La escasez de detalles sobre las estructuras fértiles en la especie de Patagonia, nos obliga a comparar nuestro material principalmente sobre la base de la morfología de las frondes con pínnulas exclusivamente esfenopterídeas. De este modo, encontramos dos especies similares: Oligocarpia mixta (Schimper) Abbott y Oligocarpia capitata (White) Abbott, del Carbonífero Superior, las cuales se diferencian entre sí por la posición de los soros, del anillo y la forma de las células del estomio (Abbott, 1954). O. mixta puede distinguirse de $O$. patagonica por sus pínnulas con lóbulos más redondeados, sin indentaciones, venas laterales con hasta tres dicotomías, y por sus esporangios reunidos en grupos de 4 a 6 (generalmente 5). Del mismo modo, O. capitata se diferencia por sus pínnulas más redondeadas, su venación lateral dividida hasta 5 veces y sus esporangios agrupados en número de 3 a 6 en los lóbulos de las pínnulas, ocupando a veces toda su superficie.

Oligocarpia gothani Halle tiene una distribución desde el Estefaniense al Pérmico Inferior en diferentes áreas de China (Shen Guanglong y Zhang Hong, 1989). Se diferencia de $O$. patagonica por la morfología de sus pínnulas y la disposición más regular y menos marginal de los esporangios.

En el Pérmico de la India se conocen dos géneros de frondes esfenopterídeas fértiles: Damudopteris (Pant y Khare, 1974) y Neomariopteris (Maithy, 1974). Damudopteris fue caracterizado por presentar esporangios aislados o laxamente agrupados en las pínnulas, con una disposición irregular pero nunca marginal. Los esporangios presentan anillos incompletos y poseen indusio. Por estos caracteres difieren de Oligocarpia patagonica sp. nov.

Maithy (1974) creó el género Neomariopteris para frondes esfenopterídeas estériles que Feistmantel (1876) determinó como Sphenopteris polymorpha. En 1975 Maithy enmienda su propia diagnosis genérica para incluir material fértil que asignó a otra especie, Dicksonia hughesii (Feistmantel, 1881). El nuevo género lo caracterizó por presentar soros circulares ubicados cerca

\section{Lámina I}

Oligocarpia patagonica sp. nov. Escala $=1 \mathrm{~cm}$.

1-2 Fragmento tripinnado, con pínnulas lobuladas y venación esfenopteroide, MPEF-PB 53a y b.

3 Sector medio de una pinna lateral proximal, MPEF-PB $52 \mathrm{c}$, paratipo.

4 Detalle de pinna con pínnulas diferenciadas en el sector proximal que pasan a lóbulos en el sector apical, MPEF-PB 51a, paratipo.
5 Fragmento tripinnado del sector medio-distal de la fronde, con detalle de la primera pínnula basiscópica, MPEF-PB 52b, paratipo.

6 Fragmento de pinna que por conservación diferencial del limbo pinnular, muestra lóbulos de aspecto cuneado, MPEF-PB 57. 
Lámina I
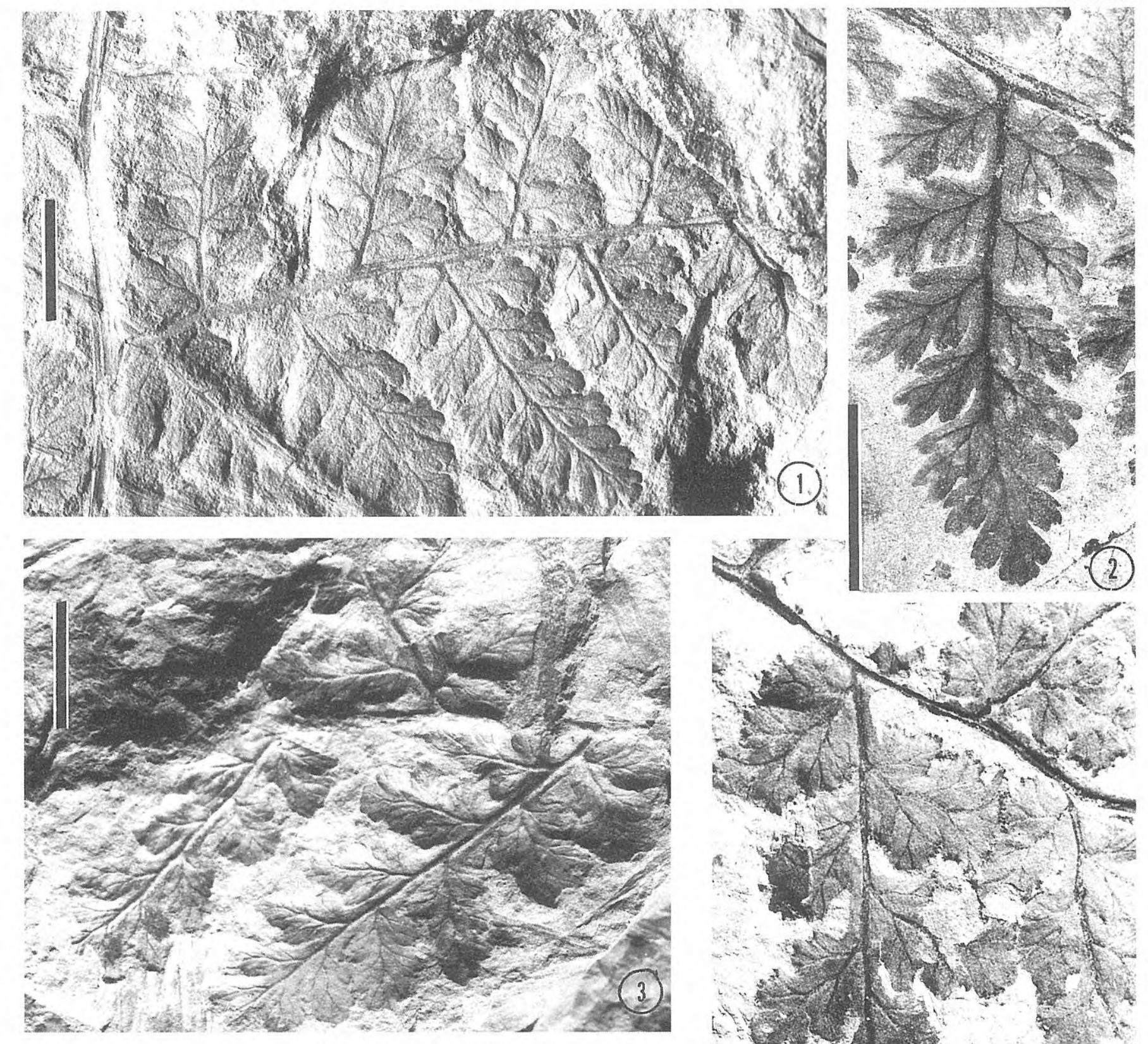
Non $12 x$

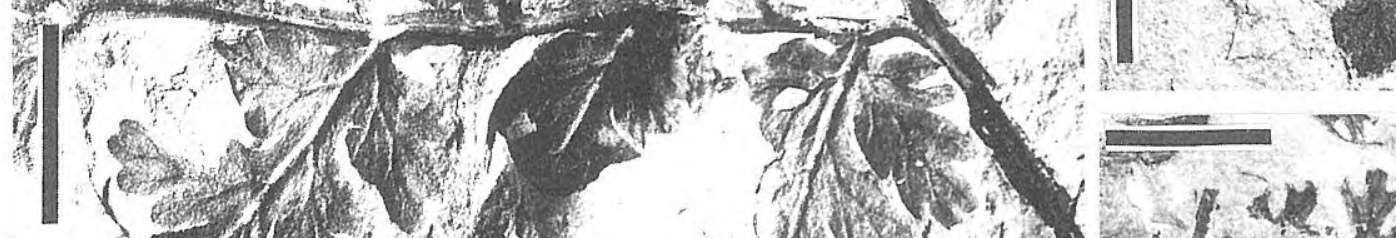
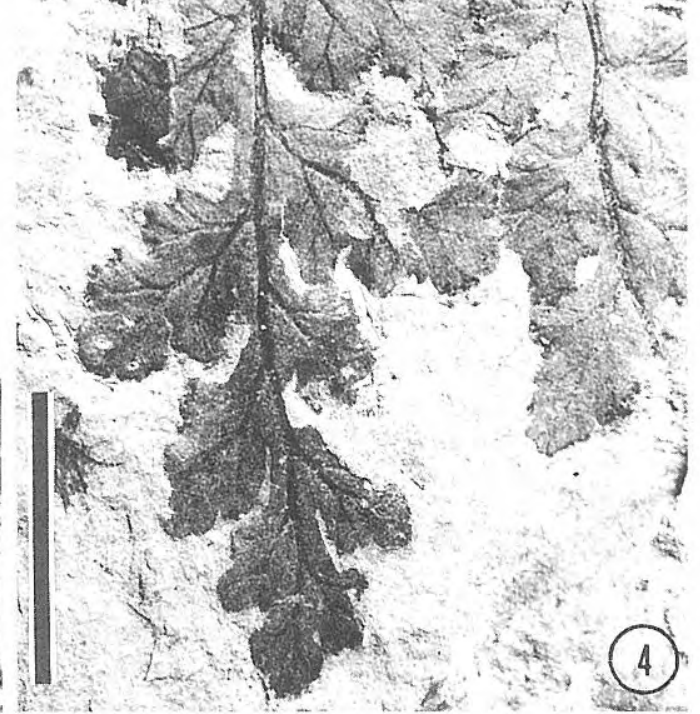

(6) (4)

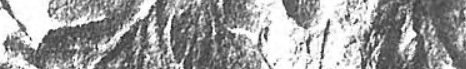

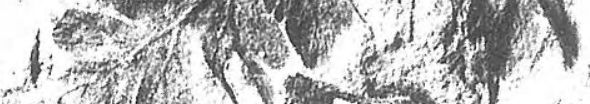

(1)

$+2(x), 3)$

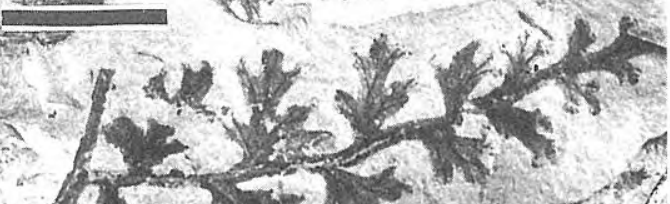

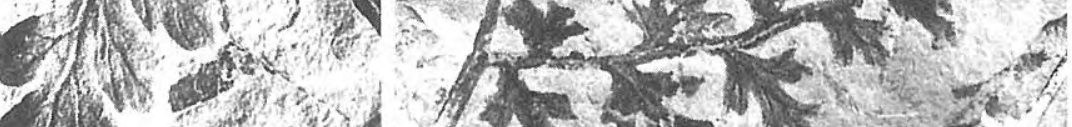

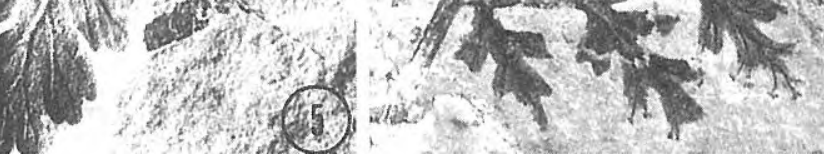




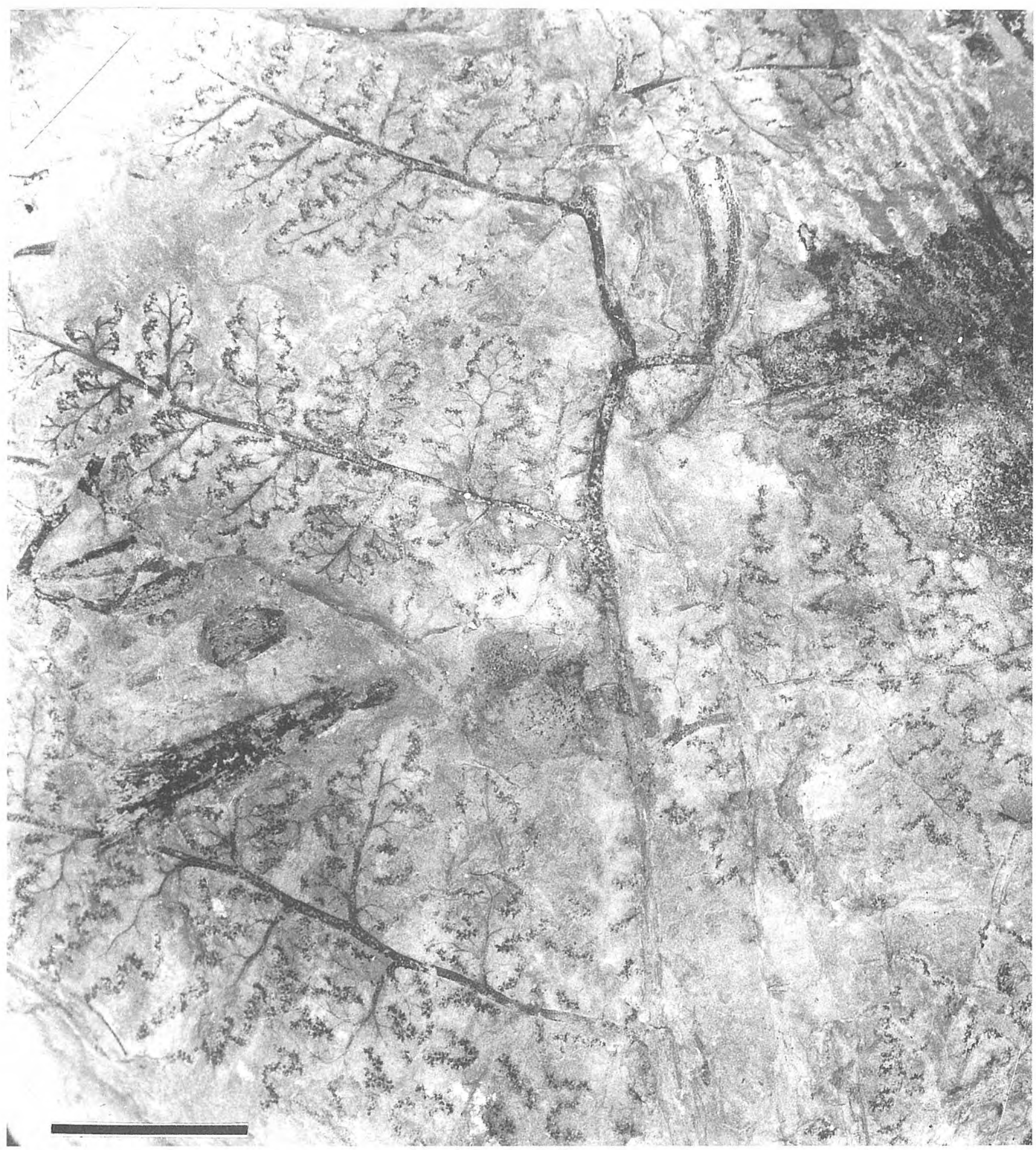

Figura 4. Oligocarpia patagonica sp. nov. Aspecto general del fragmento de fronde bipinnado, con pínnulas fértiles, MPEFPB 50a, holotipo. Escala $=1 \mathrm{~cm}$.

de los márgenes, compuestos por 4-6 esporangios libres dispuestos alrededor de un punto central. Los soros se hallan separados entre sí (Maithy, 1975, figs. 5 A-C). Esta composición de los soros, su ubicación y la falta de anillo en los esporangios diferencian el género de nuestro material.

Dichotomopteris es otro género del Pérmico de la India que tiene frondes generalmente pecopterídeas y soros (sinangios?) no marginales, con esporangios sin anillos (Maithy, 1974), caracteres éstos que los diferencian de Oligocarpia patagonica sp. nov.

En el Pérmico de Brasil se describió el género Ponsotheca (Bernardes de Oliveira, 1980) para frondes esfenopterídeas fértiles. Las fructificaciones no son marginales y se presentan como soros circulares, separados y con esporangios aparentemente sin anillos. 

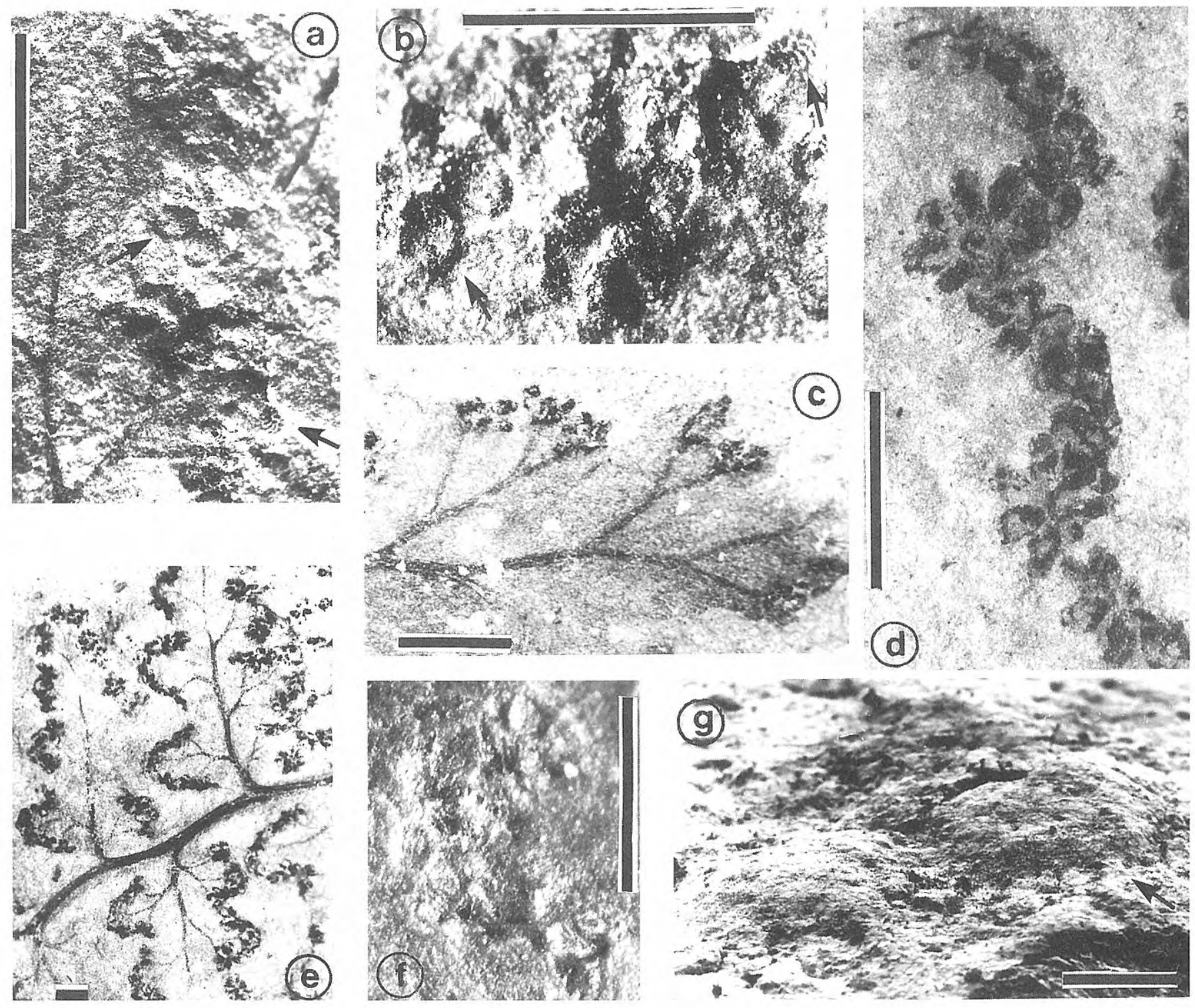

Figura 5. Oligocarpia patagonica sp. nov. a, b, d, e, f y g. Holotipo, MPEF-PB 50. a. Detalle de esporangios ubicados en el extremo distal de venas laterales. b. Detalle de anillo en los esporangios. d. Disposición de los esporangios en el margen de la pínnula, en ocasiones en forma radial, con un esporangio central. e. Detalle de las pinnulas, con esporangios marginales. f. Detalle de esporangios con células engrosadas. g. Aspecto de esporangios observados con microscopio electrónico de barrido, la flecha indica la posición del anillo ecuatorial. c. Detalle de esporangios en los extremos de venas laterales, MPEF-PB 58a. Escala en fotos a, b, c, d, e, f = $1 \mathrm{~mm}$ y en foto $\mathrm{g}=100 \mu \mathrm{m}$.

Estas características alejan dicho género de Oligocarpia patagonica sp. nov. Bernardes de Oliveira (op. cit.) sugiere que el género Neomariopteris quede como válido sólo para formas estériles y, por lo tanto, asigna al género Ponsotheca las formas fértiles de Neomariopteris ( $N$. barakarensis Srivastava, N. hughesii (Feistmantel) Maithy y $N$. polymorpha (Feistmantel) Maithy).

Chansitheca, género creado por Regé (1920) y ampliado por Halle (1927) para ejemplares del Pérmico de China, difiere por la posición de los soros que se disponen en hileras a cada lado de la vena media y tienen una forma alargada. Con estas características, en Argentina se describió Chansitheca argentina (Herbst, 1963) para el Triásico Superior (Grupo el Tranquilo, provincia de Santa Cruz), y una forma definida como
"Fílice leptosporangiada", para el Pérmico de la Formación La Golondrina, en la misma provincia (Archangelsky y de la Sota, 1960).

Chansitheca y Oligocarpia serían los más antiguos representantes de la familia Gleicheniaceae. Sin embargo, según algunos autores, la escasa información sobre caracteres estructurales de los esporangios no permitiría confirmar, por ahora, esa relación (Gandolfo et al., 1997).

\section{ASPECTOS TAFONÓMICOS Y PALEOECOLÓGICOS}

Especímenes referidos a Oligocarpia patagonica sp. nov. son bastante comunes, y en algunos casos muy 


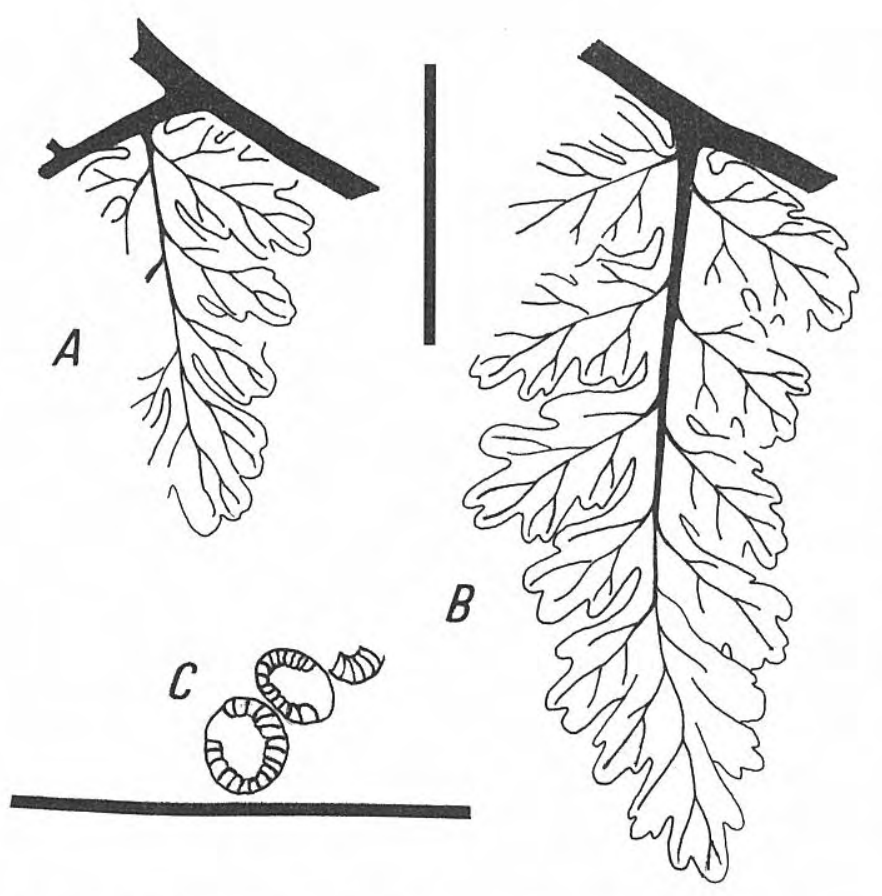

Figura 6. Reconstrucción de una pinna de orden $\mathrm{n}$ en un sector proximal de la fronde (A), en un sector medio de la fronde (B) y de algunos esporangios con parte de su anillo conservado $(C)$. Escala $=1 \mathrm{~cm}$.

abundantes, en niveles plantíferos de diversas localidades de la Formación Río Genoa. Por lo general, se los ha encontrado en facies pelíticas con muy baja fragmentación según lo evidencia el hallazgo de frondes bi y hasta tripinnadas. Ello sugiere condiciones hipoautóctonas en la formación de las tafocenosis portadoras de Oligocarpia, con el pasaje desde la planta parental al medio sedimentario, que inmediatamente incorpora los restos sin mediar procesos bioestratinómicos que obliteren sensiblemente las características morfológicas originales (Burnham et al., 1992; Behrensmeyer et al., 1992). En esta forma, ha sido posible la conservación de las partes reproductivas de la planta, incluyendo algunos detalles celulares, que no sufrieron un intenso proceso de "desecamiento" al formar parte de la "hojarasca" local previo a su incorporación al proceso sedimentario actuante.

Las tafocenosis de las cuales participa Oligocarpia muestran una amplia participación de varios grupos de plantas, entre los que se destacan otros helechos, arborescentes del tipo marattial, y varios grupos de gimnospermas, en especial glossopteridales y coníferas, con cordaitales y ginkgoales más esporádicamente asociadas. Esto parece indicar la participación de Oligocarpia en la estructura del bosque higro-mesofítico local, del cual habría formado parte, probablemente como un elemento del sotobosque con cierta penetración lumínica. Por otra parte, este helecho es muy raro o falta en conjuntos tafonómicos dominados por los elementos hidro-higrofíticos típicos de la flora pérmica del río Genoa (licófitas y esfenófitas). Más aún, es posible observar secciones plantíferas donde niveles dominados por plantas hidro-higrofíticas, al cambiar las condiciones edáficas, son sucedidos por elementos gimnospérmicos y helechos como Oligocarpia.

De acuerdo al esquema paleoambiental sugerido para la Formación Río Genoa (Andreis y Cúneo, 1989), las tafocenosis portadoras de la fílice leptosporangiada aquí estudiada, han sido registradas tanto en sectores proximales como distales del sistema deltaico que rigió la sedimentación del área. En todos los casos, se hallan vinculadas a facies suspensivas con limolitas y arcillitas depositadas en sectores interdistributarios colonizados por las plantas mencionadas anteriormente.

Los registros de Oligocarpia en el Hemisferio Norte, coincidentemente, se relacionan con las denominadas floras del Estefaniense y Pérmico Inferior (DiMichele, com. pers.). Este helecho, que fue un representante de las denominadas plantas arbustivas del Paleozoico Superior, es relativamente raro en las denominadas "coal-balls floras" y en las asociaciones vinculadas a facies epiclásticas, sin superar en ambos casos el 5\% de la biomasa. En algunos de los ejemplos estudiados, Oligocarpia tiende a aparecer en asociaciones multiespecíficas con alta diversidad y vinculadas a tafocenosis formadas en planicies de inundación. Probablemente fueron elementos de sotobosque en las comunidades originales, quizás habiendo formado parte de habitats con cierta perturbación por elevados índices de insolación (DiMichele, com. pers.). Así, habrían colonizado sustratos con la napa freática próxima a la superficie (higrofíticos), con ciertos períodos de inundación. Normalmente, los elementos asociados más comunes (y dominantes dentro del conjunto) son frondes de helechos arborescentes y secundariamente pteridospermas.

Sobre esta base, es interesante señalar, en primer lugar, la misma tendencia a colonizar similares habitats por parte de Oligocarpia en dos regiones paleoflorísticas separadas, como así también su ocurrencia en tafocenosis con una elevada diversidad, en las cuales se advierte una interesante relación de fidelidad con helechos

\section{Lámina II \\ Oligocarpia patagonica sp. nov. Escala $=1 \mathrm{~cm}$.}

1 Fragmento tripinnado de un sector distal de fronde, MPEF-PB 54.

2 Fragmento tripinnado de un sector medio de fronde, MPEF-PB 55.

3, 4 y 7 Ejemplar con pínnulas fértiles y estériles. 3 y 4 : detalle de pínnulas fértiles que por conservación diferencial muestran un aspecto cuneado. 7. detalle de pínnulas estériles, BAPB 4531, paratipo. Fragmento del sector más distal de la fronde con pinnas subopuestas, MPEF-PB 56. 


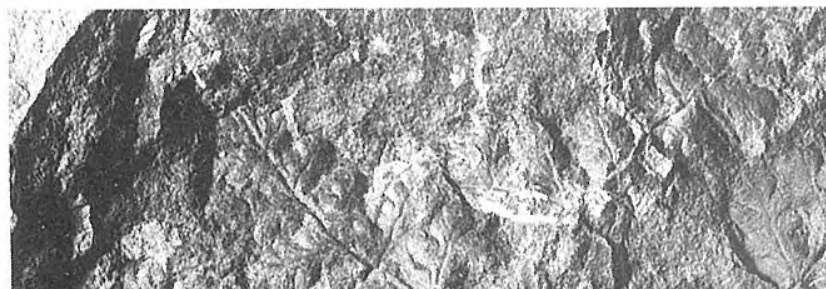

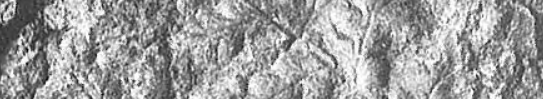

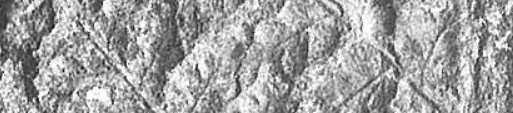

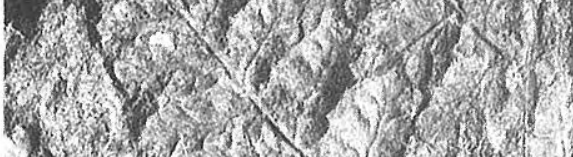

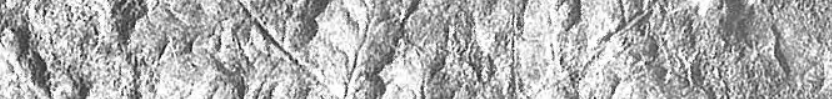

(2) if

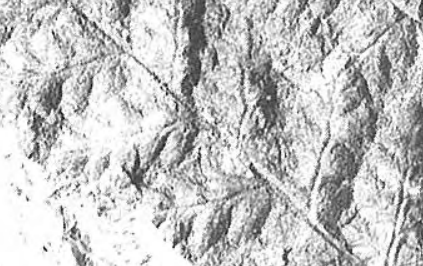

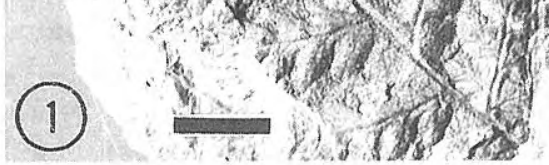
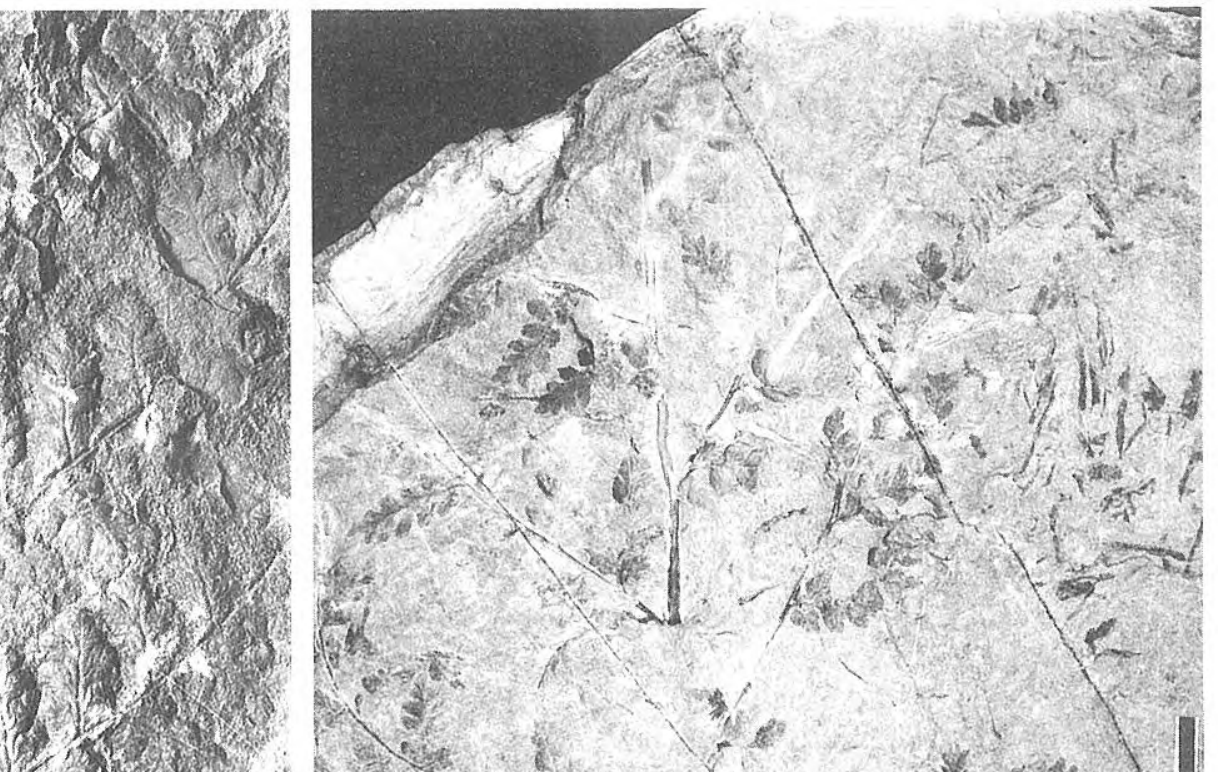
the

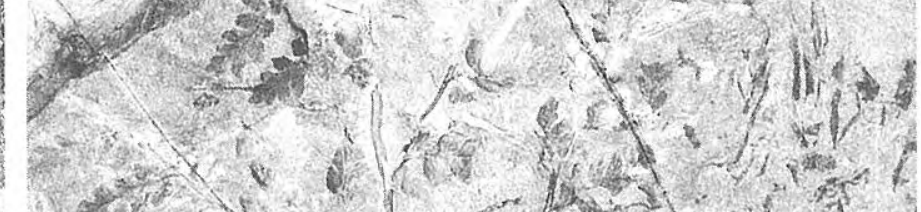

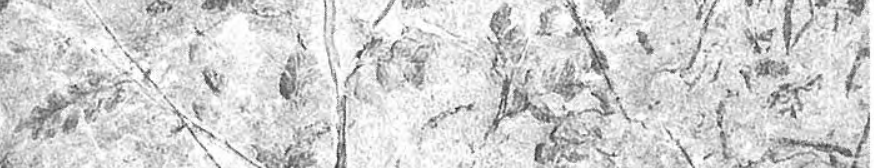

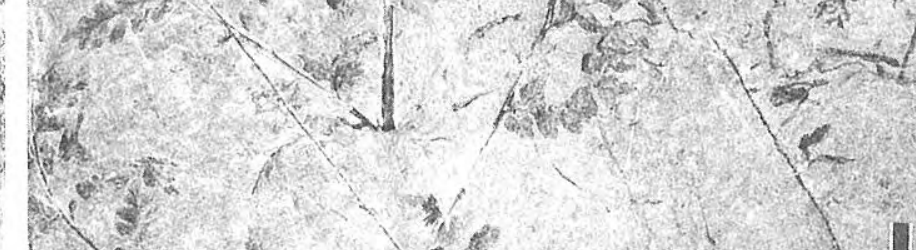
(1)
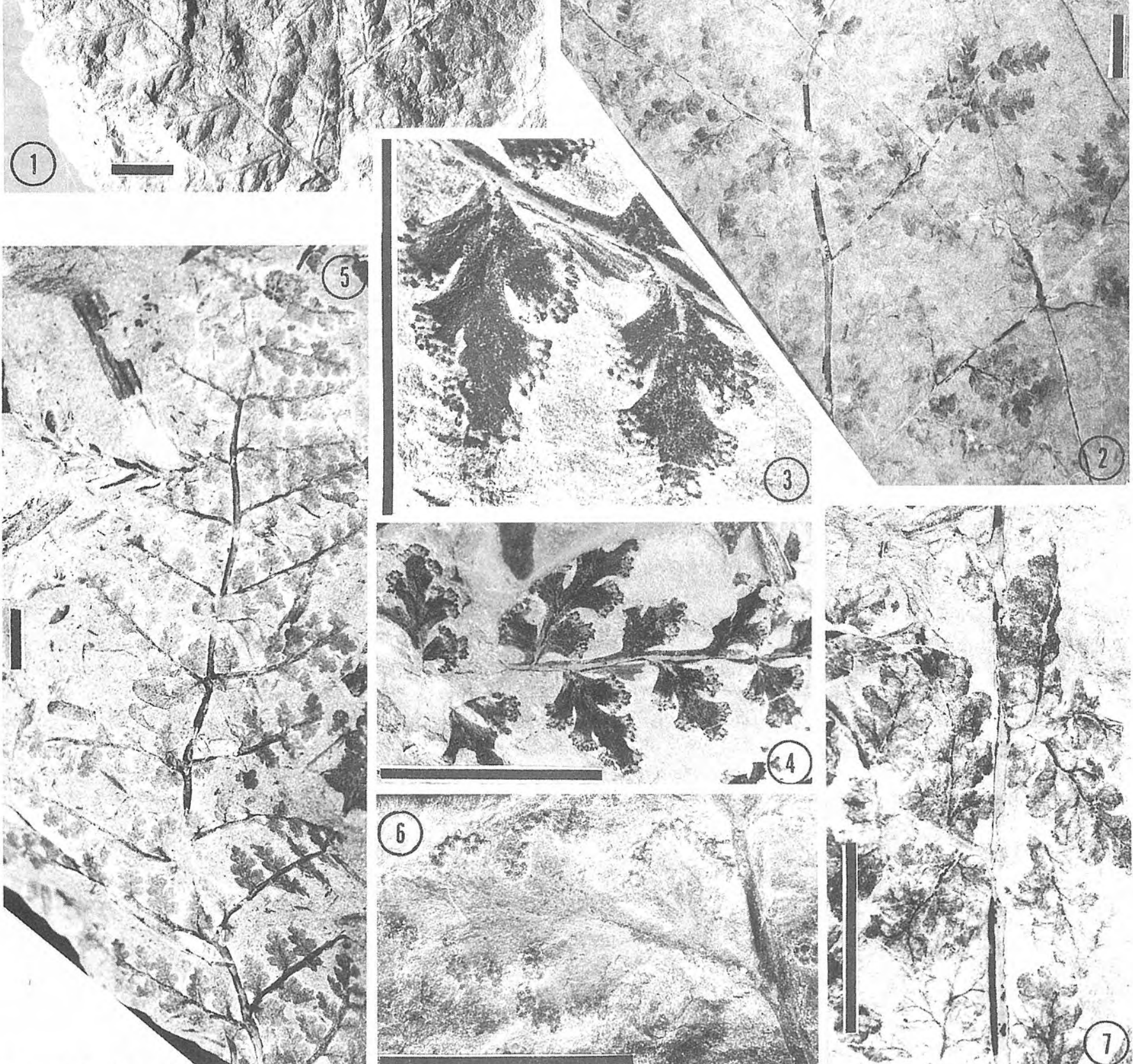

$x+\frac{1}{2}+2$

$1+x^{2}$

(1)

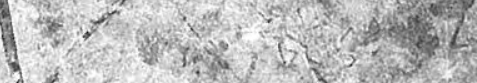


arborescentes en ambos casos. La principal diferencia quizás esté dada por la mayor participación de pteridospermas en las asociaciones de la región euroamericana, mientras que en Patagonia se advierte un predominio de otras gimnospermas (en especial coníferas y glossopterídeas), no obstante la rara presencia de pteridospermas en algunos niveles.

\section{BIBLIOGRAFÍA}

Abbott, M. L., 1954. Revision of the Paleozoic fern genus Oligocarpia. Palaeontographica, 96, 39-65.

Andreis, R. R. and Cúneo, N. R., 1989. Late Paleozoic high constructive deltaic sequences from Northwestern Patagonia, Argentina Republic. Journal of South American Earth Science, 2, 10-24.

Archangelsky, S., 1958. Estudio geológico y paleontológico del Bajo de la Leona (Santa Cruz). Acta Geológica Lilloana, 2, 5-133.

Archangelsky, S. y Cúneo, N. R., 1985. Zonación del Pérmico continental argentino sobre la base de sus plantas fósiles. Memorias 3er. Congreso Latinoamericano Paleontología, México, 143-153.

Archangelsky, S. y Cúneo, N. R., 1986. Corynepteris australis sp. nov. primer registro de una Coenopteridal en el Pérmico Inferior de Chubut, Argentina. Actas IV Congreso Argentino de Paleontología y Bioestratigrafía, Mendoza, 1, 177-185.

Archangelsky, S. y Sota, E. de la. 1960. Contribución al conocimiento de las Fílices pérmicas de la Patagonia Extraandina. Acta Geológica Lilloana, 3, 85-126.

Archangelsky, S., Césari, S. N. and Cúneo, N. R., 1995. Permian ferns from Patagonian Basins of Argentina: a review. International Congress on CarboniferousPermian, Polonia, Abstr., 8.

Behrensmeyer, A., Damuth, É., DiMichele, W., Potts, R., Dieter Suess, H. and Wing, S., 1992. Terrestrial ecosystems through time. Evolutionary paleoecology of terrestrial plants and animals. The University of Chicago Press, 568 pp.

Bernardes de Oliveira, M., 1980. Nouveau genre néomarioptéridien fertile de la flore à Glossopteris du Bassin de Paraná au Brésil. Boletim Instituto de Geociências, Universidade de São Paulo, 11, 113-119.

Bower, F. O., 1935. The origin of a Land Flora. (1959 reprint Hafner Publ. Co., New York). 727 pp.

Brousmiche, C., 1983. Les fougeres sphénoptéridiennes du Bassin Houiller Sarro-Lorrain. Société Géologique du Nord, Publication no. 10, 480 pp.
Burnham, R., Wing, S. and Parker, G., 1992. The reflection of deciduous forest communities in leaf litter: implications for autochtonous litter assemblages from the fossil record. Paleobiology, 18, 30-49.

Cúneo, N. R., 1987. Estudio geológico y paleontológico de los afloramientos meridionales de la Formación Río Genoa, Pérmico Inferior de Chubut, Argentina. Tesis Doctoral, Universidad de Buenos Aires, 464 pp. (inédito).

Cúneo, N. R. y Archangelsky, S., 1987. Sobre la presencia de helechos arborescentes en la Formación Río Genoa, provincia de Chubut, Argentina. VII Simposio Argentino de Paleobotánica y Palinología, Actas, 51-54.

Feistmantel, O., 1876. On some fossil plants from the Damuda Series in the Raniganj coal-field, collected by Mr. J. Wood Mason. Journal Asiatic Society Bengal, 45, 329-382.

Feistmantel, O., 1881. The fossil flora of Gondwana System. II. The flora of the Damuda-Panchet Divisions. Memoirs Geological Survey India, Palaeontología Indica, 3, 1-49.

Gandolfo, M., Nixon, K., Crepet, W. and Ratcliffe, G., 1997. A new fossil fern assignable to Gleicheniaceae from Late Cretaceous sediments of New Jersey. American Journal of Botany, 84, 483-493.

Gastaldo, R. and Boersma, M., 1983. A reinvestigation of Early Pennsylvanian species of Mariopteris from the Appalachian Region. I. Karinopteris, Mariopteris and the "pottsvillea complex". Review of Palaeobotany and Palynology, 38, 185-226.

Halle, T. G., 1927. Palaeozoic plants from Central Shansi. Palaeontología Sinica ser. A, 2, 316 pp.

Herbst, R., 1963. Chansitheca argentina n.sp. del Triásico superior de Santa Cruz, Patagonia. Ameghiniana, 3, 108112.

Maithy, P., 1974. A revision of the Lower Gondwana Sphenopteris from India. The Palaeobotanist, 21, 70-81.

Maithy, P., 1975. Some contribution to the knowledge of Indian Lower Gondwana ferns. The Palaeobotanist, 22, 29-37.

Pant, D. and Khare, P., 1974. Damudopteris gen. nov. a new genus of ferns from the Lower Gondwanas of the Raniganj coalfield, India. Proceedings of the Royal Society of London B, 186, 121-135.

Regé, R., 1920. Note su alcuni vegetali del carbonifero della Cina. Atti della Società Italiana di Scienze Naturali e del Museo civico di Storia Naturale in Milano, 59, 183-196.

Shen Guauglong and Zhang Hong, 1989. Carboniferous and Permian Megafloral assemblage zones of Lonshoushan mountains, western Gansu, China. Compte Rendu XI Congress International Stratigraphie Geologie Carbonifère, 3, 149-157. 